\title{
Genome-Wide Identification of WRKY Family Genes and Analysis of Their Expression in Response to Abiotic Stress in Ginkgo biloba L.
}

\author{
Shuiyuan $\mathrm{CHENG}^{\mathrm{la}}$, Xiaomeng $\mathrm{LIU}^{2 \mathrm{~b}}$, Yongling LIAO${ }^{2}$, Weiwei ZHANG ${ }^{2}$, \\ Jiabao $\mathrm{YE}^{2}$, Shen $\mathrm{RAO}^{2}$, Feng $\mathrm{XU}^{2 *}$ \\ ${ }^{1}$ Wuhan Polytechnic University, National R\&D Center for Se-rich Agricultural Products Processing Technology, Wuhan, Hubei 430023, \\ China;s_y_cheng@sina.com \\ ${ }^{2}$ Yangtze University, College of Horticulture and Gardening, Jingzhou, Hubei 434025, \\ China;LiuXM925@163.com; liaoyongling@yeah.net;wwzhangchn@163.com;yejiabao13@163.com; raoshen1989@163.com; \\ xufeng198@126.com ('corresponding author) \\ ${ }^{a, b}$ These authors contributed equally to this work and should be considered co-first authors
}

\begin{abstract}
Ginkgo biloba is widely planted, and the extracts of leaves contain flavonoids, terpene esters and other medicinal active ingredients. WRKY proteins are a large transcription factor family in plants, which play an important role in the regulation of plant secondary metabolism and development, as well as the response to biotic and abiotic stress. In our study, we identified 40 genes with conserved WRKY motifs in the G. biloba genome and classified into groups I (groups I-N and -C), II (groups IIa, b, c, d, and e), and III, which include 12, 26, and 2 GbWRKY genes, respectively. Meanwhile, the expression patterns of 10 GbWRKY (GbWRKY2, GbWRKY3, GbWRKY5, GbWRKY7, GbWRKY11, GbWRKY15, GbWRKY23, GbWRKY29, GbWRKY31, GbWRKY32) under different tissue and abiotic stress conditions were analyzed. Under stress treatment, the expression patterns of 10 WRKY genes were changed. 10 ginkgo WRKY transcription factors were induced by ETH and SA, but there are two different induced response modes. The expression of $10 \mathrm{WRKY}$ genes was inhibited under low temperature, high temperature and MeJA hormone induction. Most WRKY genes were up-regulated under the induction of high salt and ABA. GbWRKYs were differentially expressed in various tissues after abiotic stress and plant hormone treatments, thereby indicating their possible roles in biological processes and abiotic stress tolerance and adaptation. Our results provided insight into the genome-wide identification of GbWRKYs, as well as their differential responses to stresses and hormones. These data can also be utilized to identify potential molecular targets to confer tolerance to various stresses in G. biloba.
\end{abstract}

Keywords: genome-wide; Ginkgo biloba L.; phytohormone; stress response; WRKY

\section{Introduction}

Plants constantly encounter adverse conditions, such as water deficiency, salinity, threshold temperatures, nutrient starvation, and variable light conditions. Plants have evolved with intricate mechanisms at multiple levels to adapt to these conditions. At the molecular level, plant devotes a large portion of their genome capacity to transcription. Transcription factors are composed of a gene family of regulatory proteins in plant and exhibit a very diverse expression range. A total of 320370 transcription factors from 165 species are identified thus far (Jin et al., 2017). Among these transcription factors, WRKY proteins play important regulatory roles in many biological processes, such as plant development, metabolism, and responses to biotic and abiotic stresses (Rushton et al., 2010). For example, Arabidopsis thaliana WRKY 6 (AtWRKY6) is influenced by several external and internal signals that are often involved in triggering senescence processes and plant defense responses (Li et al., 2017). AtWRKY18 can bind directly to different W-boxes at the AtWRKY53 promoter region and repress the expression of AtWRKY53, which is an important senescence regulator of the AtWRKY family (Potschin et al., 2014). From a developmental perspective, AtWRKY6 is involved in the growth of lateral roots (Stetter et al., 2017). OsWRKY74 modulates tolerance to phosphate starvation in rice (Dai et al., 2016). The WRKY 
genes also play an important role in secondary metabolism (Han et al., 2014; Spyropoulou et al., 2014). The physiological responses modulated by these WRKYs also include some signaling substances, such as salicylic acid (SA) (Li et al., 2004), jasmonic acid (JA) (Wei, 2010), and abscisic acid (ABA) (Sun et al., 2014). Numerous studies have also shown that many WRKY genes are involved in response to drought (Zhang et al., 2017), heat (Wang et al., 2017), and cold (Luo et al., 2017). A single WRKY gene often shows transcription activity in response to several stresses, thereby indicating that it has different regulatory function in diverse stress responses (Wang et al., 2017). Thus, a genome-wide analysis of G. biloba WRKY genes should help reveal the underlying complex molecular mechanisms of WRKY proteins in response to various stresses.

The WRKY proteins is one of the largest transcription factor superfamilies in plant and defined by a 60 amino acidconserved sequence named WRKY domain (WD), which contains WRKYGQK motif at the $\mathrm{N}$-terminal and a $\mathrm{Zn}$ finger-like motif at the C-terminal (Agarwal et al., 2011). In some WRKY proteins, the heptapeptide WRKYGQK motif shows slight variations, which have been replaced by WRKYGKK and WRKYGEK (Chen et al., 2010). The WRKY transcription factors in $A$. thaliana can be classified into three groups on the basis of the number of WDs and the nature of their Zn-finger motif (Eulgem et al., 2000). Group I members contain two WRKY conserved domains, whereas the other groups of proteins are composed of a single WD. Both groups I and II have a $\mathrm{C} 2 \mathrm{H} 2$-type $\mathrm{Zn}$ finger motif (i.e., C-X4-5-C-X22-23-H-X1-H). Group II is divided into five subgroups (i.e., IIa-e) on the basis of the additional amino acid motifs present outside the WD. Group III differs from groups I and II in altering $\mathrm{C} 2 \mathrm{HC} \mathrm{Zn}$ finger motif (i.e., C-X7-C-X23-H-X-C) (Rushton et al., 2010).

Ginkgo biloba L. is a living fossil that has remained essentially unchanged in terms of gross morphology for more than 200 million years (Lin et al., 2011). G. biloba has become widespread and popular worldwide due to its outstanding resistance or tolerance to both herbivores and pathogens (Guan et al., 2016). Ginkgolides and bilobalide, which are collectively called terpene trilactones, are the most unique components of $G$. biloba extracts and have been linked to resistance to fungi (Pan et al., 2016) and possibly to endophytic bacteria (Yang et al., 2015). The biosynthesis of bilobalide was highly correlated with the mevalonic acid pathway, and the biosynthesis of ginkgolides was highly correlated with the methylerythritol 4-phosphate pathway (Chen et al., 2015). Most structural genes of the terpene trilactone biosynthetic pathway in $G$. biloba, including $D X S$ (Gong et al., 2006; Kim et al., 2006a), DXR (Gong et al., 2005), MECT (Kim et al., 2006b), CMK (Kim et al., 2008a), MECS (Kim et al., 2006c), HDS (Kim and Kim, 2009), HDR (Kim et al., 2008b; Lu et al., 2008), FPS (Wang et al., 2004), GGPPS (Liao et al., 2004), LPS (Schepmann et al., 2001), HMGR (Shen et al., 2016), MVD (Pang et al., 2006), AACT and MVK (Chen et al., 2017), have been isolated. WRKY binding sites are found in the promoter regions of several ginkgo terpene trilactone biosynthetic gene, such as GbLPS (Kim et al., 2012), GbDXS (Xu et al., 2013), GbGGPPS (Xu et al., 2013), GbHMGR (Liao et al., 2015a), GbMVD (Liao et al., 2015b), GbIDS (Kang et al., 2013), GbMECP and GbMECT (Cheng et al., 2015). However, knowledge on the function of ginkgo WRKY genes is limited because on the limited works that was previously reported (Liao et al., 2015c; Liao et al., 2016). A draft of the genome (Guan et al., 2016) and numerous transcriptomes was reported. In the current study, we performed a genome-wide (Wang et al., 2010; Han et al., 2005; He et al., 2015; Du et al., 2016) identification of the $W R K Y$ gene family in G. biloba. The ginkgo WRKY transcription factor family has 40 members. Detailed analyses including gene classification, gene phylogeny, conserved motif composition, and expression pattern were performed. A total of $10 G b W R K Y$ genes were further investigated for the alterations of expression patterns in response to abiotic stresses via real-time quantitative RT-PCR. Our results will aid in understanding the roles of the $W R K Y$ genes in ginkgo development, defense responses, and terpene trilactone biosynthesis. The results may provide valuable information for further identification of the function of this gene family in $G$. biloba.

\section{Materials and Methods}

Identification of WRKY gene family members in G. biloba

$G$. biloba unannotated genome sequences were downloaded from GigaDB (http://gigadb.org/) (Guan et al., 2016). HMM profile of WRKY DNA-binding domain (PF03106) downloaded from Pfam protein family database (http://pfam.sanger.ac.uk/) was exploited for the identification of $W R K Y$ genes from ginkgo genome using HMMER 3.1 (http://hmmer.org/). The default parameters were employed. All non-redundant gene sequences searched from the ginkgo genome data were collected and then compared with each other. The transcriptome of $G$. biloba was sequenced using four organs, including leaves of male and female tree, stamens, and gynoecia (our unpublished data). Subsequently, the key word "WRKY" was used as queries to search against the annotated unigenes. Three published $G$. biloba WRKY (GbWRKY) protein sequences (GbWRKY2 with ID: ALC78712.1, GbWRKY11 with ID: ALC78713 and GbWRKY31 with ID: AQU43027) were downloaded from GeneBank (https://www.ncbi.nlm.nih.gov/genbank/). Sequences from genome and transcriptome and published GbWRKY proteins that shared $>95 \%$ matches were considered redundant. Furthermore, multiple alignments among those these putative WRKY proteins were performed to avoid repetition and the WRKY domain was searched using the SMART program (http://smart.embl-heidelberg.de/). Candidate proteins with an incomplete WRKY domain were removed (Gb_28473, Gb_41027, Gb_07810 and $\mathrm{Gb}$ 02625) and not used in subsequent analysis, and the final identified $G b W R K Y$ genes were named $G b W R K Y 1$ to GbWRKY40 (Table 1). 
1102

Table 1. Identification of the $W R K Y$ gene in the ginkgo genome and transcriptome

\begin{tabular}{|c|c|c|c|c|}
\hline Gene ID & Gene symbol & Subgroup & Related publications & Length (bp) \\
\hline Gb_31953 & GbWRKY1 & I & & 659 \\
\hline Gb_25118 & GbWRKY2 & I & (Liao et al., 2015c) & 775 \\
\hline Gb_32055 & GbWRKY3 & I & & 775 \\
\hline Gb_36273 & GbWRKY4 & I & & 548 \\
\hline Gb_01391 & GbWRKY5 & I & & 861 \\
\hline Gb_36184 & GbWRKY6 & I & & 679 \\
\hline T1_20451 & GbWRKY7 & I & & 673 \\
\hline Gb_02351 & GbWRKY8 & $\mathrm{IIb}$ & & 526 \\
\hline Gb_39366 & GbWRKY9 & IIb & & 707 \\
\hline Gb_23334 & GbWRKY10 & IIb & & 687 \\
\hline Gb_15478 & GbWRKY11 & IId & (Liao et al., 2016) & 402 \\
\hline T1_5610 & GbWRKY12 & $\mathrm{IIb}$ & & 261 \\
\hline T1_7872 & GbWRKY13 & IIb & & 300 \\
\hline Gb_40261 & GbWRKY14 & IIc & & 226 \\
\hline Gb_26412 & GbWRKY15 & IIc & & 190 \\
\hline Gb_26413 & GbWRKY16 & IIc & & 248 \\
\hline Gb_40257 & GbWRKY17 & IIc & & 240 \\
\hline Gb_26411 & GbWRKY18 & IIc & & 248 \\
\hline Gb_40207 & GbWRKY19 & IIc & & 266 \\
\hline Gb_16917 & GbWRKY20 & IIc & & 273 \\
\hline Gb_05024 & GbWRKY21 & IIc & & 233 \\
\hline Gb_05026 & GbWRKY22 & IIc & & 388 \\
\hline Gb_17074 & GbWRKY23 & IIc & & 467 \\
\hline Gb_01873 & GbWRKY24 & IIc & & 485 \\
\hline Gb_26894 & GbWRKY25 & IIc & & 305 \\
\hline CL3411 & GbWRKY26 & IIc & & 509 \\
\hline CL6024 & GbWRKY27 & IIc & & 446 \\
\hline Gb_16513 & GbWRKY28 & IId & & 360 \\
\hline Gb_01527 & GbWRKY29 & IId & & 367 \\
\hline Gb_12539 & GbWRKY30 & IId & & 252 \\
\hline Gb_06156 & GbWRKY31 & IIb & (Li et al., 2016) & 427 \\
\hline T1_13300 & GbWRKY32 & IId & & 356 \\
\hline CL7159 & GbWRKY33 & IId & & 362 \\
\hline Gb_25547 & GbWRKY34 & IIe & & 383 \\
\hline Gb_05176 & GbWRKY35 & IIe & & 497 \\
\hline Gb_25334 & GbWRKY36 & IIe & & 274 \\
\hline Gb_03346 & GbWRKY37 & IIe & & 608 \\
\hline Gb_17623 & GbWRKY38 & IIc & & 131 \\
\hline Gb_00547 & GbWRKY39 & III & & 579 \\
\hline Gb_00545 & GbWRKY40 & III & & 481 \\
\hline
\end{tabular}

\section{Sequence analysis}

For the analysis of WDs of $G$. biloba, 6 AtWRKY protein sequences from different groups/subgroups were downloaded from The Arabidopsis Information Resource (TAIR, http://www.arabidopsis.org/). The 65 amino acid spanning the WRKY core domain of all GbWRKY proteins and selected AtWRKY proteins (AtWRKY2, AtWRKY6, AtWRKY7, AtWRKY8, AtWRKY14, and AtWRKY30) were used to create multiple protein sequence alignments by using Clustal X2 with default settings. Motif detection was performed with MEME 4.10.1 (http://meme-suite.org/tools/meme). The parameters are as follows: any number of repetitions, a maximum of 20 motifs, and an optimum motif width between 6 and 50 residues. A structural motif annotation was also performed using the Pfam (Finn et al., 2016) and SMART (Letunic et al., 2015). The exon-intron organization of $G$. biloba WRKY genes was determined by comparing the predicted coding sequences with their corresponding full-length sequences by using the online program Gene Structure Display Server (http://gsds.cbi.pku.edu.cn) (Guo et al., 2007). Analysis results include the number and location of exons and introns.

\section{Phylogenetic analysis of WRKY proteins}

To analyze the subgroups of the putative ginkgo WRKY family, we downloaded 71 AtWRKY proteins from TAIR. The amino acid sequences of Hevea brasiliensis HbWRKY1 
(ADF45433.1), Coptis japonica var. dissecta CjWRKY1 (BAF41990.1), Taxus wallichiana var. chinensis TwWRKY (AEW91476.1), Gossypium arboretum GaWRKY1 (AAR98818.1), Artemisia annua AaWRKY1 (ACJ12926.1), Panax quinquefolius PqWRKY1 (AES92925.1), and Catharanthus roseus CrWRKY1 (ADT82685.1), which were involved in biological synthesis of secondary metabolites, were downloaded from GenBank. A neighbor-joining tree was constructed by MEGA 6.0 with the following parameters: Poisson correction, complete deletion, and bootstrap analysis with 1000 replicates. The sequences of the 40 GbWRKYs, 71 AtWRKYs, HbWRKY1, CjWRKY1, TwWRKY, GaWRKY1, AaWRKY1, PqWRKY1, and CrWRKY1 used for tree building are listed in Table $S 1$.

Expression profile of GbWRKY under the hormones and stress treatments

The 14-year-old grafts of $G$. biloba were grown in a garden at Yangtze University in Hubei Province, China. To investigate the tissue expression of GbWRKY genes, we collected the leaves, stems, roots, male and female strobili of $G$. biloba grafts, immediately frozen in liquid nitrogen, and kept at $-80{ }^{\circ} \mathrm{C}$ prior to RNA extraction. The suspended callus lines, which were prepared according to the method provided by Liao (Liao et al., 2015a), were used as materials in the abiotic stresses and hormonal treatments to maintain consistency. The callus lines were mixed with $100 \mu \mathrm{mol} \mathrm{L}^{-1}$ MeJA, $100 \mu \mathrm{mol} \mathrm{L}{ }^{-1} \mathrm{ABA}, 100 \mu \mathrm{mol} \mathrm{L}{ }^{-1} \mathrm{SA}, 40 \mu \mathrm{mol} \mathrm{L}{ }^{-1}$ ETH, and $200 \mu \mathrm{mol} \mathrm{L}{ }^{-1} \mathrm{NaCl}$ by using ginkgo callus without any treatment as control. The chilling and heat treatments were performed by placing the callus lines in a 4 ${ }^{\circ} \mathrm{C}$ and $40{ }^{\circ} \mathrm{C}$ growth room, respectively. The control was in a $25^{\circ} \mathrm{C}$ growth room. The samples were harvested at 3, 6, $12,24,48$, and $72 \mathrm{~h}$ after treatment, immediately frozen in liquid nitrogen, and kept at $-80^{\circ} \mathrm{C}$ until use.

\section{$R N A$ extraction and quantitative $R T-P C R$ analysis}

The total RNAs of roots, stems, leaves, male flowers, female flowers, and different stress-treated samples of $G$. biloba were extracted according to the instructions of the MiniBEST Plant RNA Extraction kit. cDNA was synthesized by reverse transcription polymerase chain reaction using the Transcriptor First Strand cDNA Synthesis Kit (Roche, Germany). qRT-PCR technique was used to detect the expression level of WRKY genes, and glyceraldehyde-3-phosphate dehydrogenase gene (GbGAPDH, GenBank accession no. L26924) was selected as the reference gene. On the basis of the random selection of $10 \mathrm{WRKY}$ transcription factor unigene fragments and $G b G A P D H$ sequences, we designed the qRT-PCR primers according to the AceQ ${ }^{\circ}$ qCR $S$ SBR $^{\circ}$ Green Master Mix (Without ROX) kit's real-time PCR primers (Table 2). qRT-PCR was conducted using a Bio-Rad Mini Opticon ${ }^{\text {TM }}$ Real-time PCR Mini Cycler (BioRad, Hercules, CA, USA) with SYBR Premix Ex Taq ${ }^{\mathrm{TM}}$ II Kit (Dalian TaKaRa) according to the method of Xu et al. (2014). The reaction system was $20 \mu \mathrm{L}$, and the following qPCR conditions recommended by the manufacturer were used: 40 cycles of $95^{\circ} \mathrm{C}$ for $30 \mathrm{~s}, 95^{\circ} \mathrm{C}$ for $5 \mathrm{~s}$, and $60{ }^{\circ} \mathrm{C}$ for $30 \mathrm{~s}$ with the addition of a dissolution curve. Three biological replicates were performed for each gene under different tissue and stress conditions by using ultrapure water as a negative control. The $2 \Delta \Delta^{\mathrm{Ct}}$ method (Schmittgen and Livak, 2008) was used to analyze the expression level of the WRKY gene. qRT-PCR data were technically replicated with error bars representing mean $\pm \mathrm{SD}(\mathrm{n}=3)$.

\section{Statistical analysis}

Data were analysed with one-way ANOVA by using SPSS 11.0 for Windows (SPSS Inc., Chicago, IL, USA), and mean differences were compared with the lowest SD (LSD) test by using SPSS 17.0 software. The $p$ value of $<0.05$ was considered statistically significant.

\section{Results}

A total of 40 WRKY proteins were obtained in $G$. biloba genome and transcriptome. The obtained GbWRKY sequences are shown in Table S1. The GbWRKY proteins contained 131 (GbWRKY38) to 861 (GbWRKY5) amino acid residues. The conserved WD was approximately 60 amino acid residues long. Multiple alignments were performed to clarify the sequence features of 40 predicted GbWRKY domain sequences. The 47 conserved WDs of GbWRKYs are presented in Fig. 1. In GbWRKY4N and GbWRKY20, the WRKYGQK motifs in the WDs were replaced by WRKYGKK. In GbWRKY21 and GbWRKY22, the WRKYGQK motifs in the WDs were replaced by WRKYGRK. In GbWRKY1, the WRKYGQK motifs in the WDs were replaced by WRKYAQK. In GbWRKY18, GbWRKY17,

Table 2. Primers for qRT-PCR

\begin{tabular}{ccc}
\hline Gene & Primer forward sequence $\left(5^{\prime}-3^{\prime}\right)$ & Primer reverse sequence $\left(5^{\prime}-3^{\prime}\right)$ \\
\hline GAPDH & GGTGCCAAAAAGGTGGTCAT & CAACAACGAACATGGGAGCAT \\
GbWRKY2 & GGTCTTGGGGTGTTTGGTCT & GGAACTTCTGTTTGCTGCCTCT \\
GbWRKY29 & AGTGCCAGCAATCAGCGTT & CCCTTGATGGGTTTCTGTCC \\
GbWRKY7 & AGACGATCATCCTATGCCAAGA & CAGTATGTATCCTGTCCCCTTCA \\
GbWRKY3 & AGCCTTGGAATAGCTGGTGC & CAAGGAAAGATTGAACCGAAAC \\
GbWRKY11 & TGTAAGAGGTTGCCCTGCTAGA & TGGTTATGTTCTCCCTCGTATGT \\
GbWRKY15 & ACTACCCATTCTTCTACCGAACTTG & TTGATGAACTGTCGGTGGTGG \\
GbWRKY32 & ATCAGTCCACAAGCAGACCTCA & TTGTCATTAGCAACACTGCCATC \\
GbWRKY31 & CTGCGGTTTCTCAACAGTCTC & CCAGAAACTTGGAATCCTTCACAC \\
GbWRKY5 & GCAATGGCGGATTTGAAGTC & GCCCAGAATACAGACTTGCTTGA \\
\hline
\end{tabular}


1104

GbWRKY15, GbWRKY16, GbWRKY14, and GbWRKY19, the WRKYGQK motifs in the WDs were replaced by WRKYGEK, which is one of the most common variants of motifs.

As described in the Introduction, almost all WRKY transcription factors in all plant species can be divided into three categories, namely, groups I, II, and III, on the basis of the number of WDs and the features of the C-terminal $\mathrm{Zn}$ finger structures. The WRKY proteins in group II can be further divided into five subgroups, namely, groups IIa, b, c, d, and e. In our analysis, 40 Ginkgo WRKY transcription factors were divided into three categories (Fig. 1). Out of these $40 \mathrm{WRKY}$ transcription factors, 12 belonged to group I; their group I-N and I-C were clustered with groups I-N and I-C of A. thaliana, respectively. The $\mathrm{Zn}$ finger structure type was C-X4-5-C-X22-23-H-X1-H (C2H2). Most G. biloba WRKY transcription factors (26 in total) belonged to group II. These transcription factors were clustered together with four subgroups, namely, groups IIb, c, d, and $\mathrm{e}$, of $A$. thaliana. The number of $G$. biloba WRKY transcription factors belonging to group IIc was the highest (13), whereas groups IIb, d, and e only had 4 transcription factors each. No $G$. biloba WRKY transcription factor belonged to group IIa, and GbWRKY1 showed a CYH2type $\mathrm{Zn}$ finger domain. This $\mathrm{Zn}$ finger domain has not been reported in the WRKY family of other plants. Only two GbWRKY genes were clustered into group III.

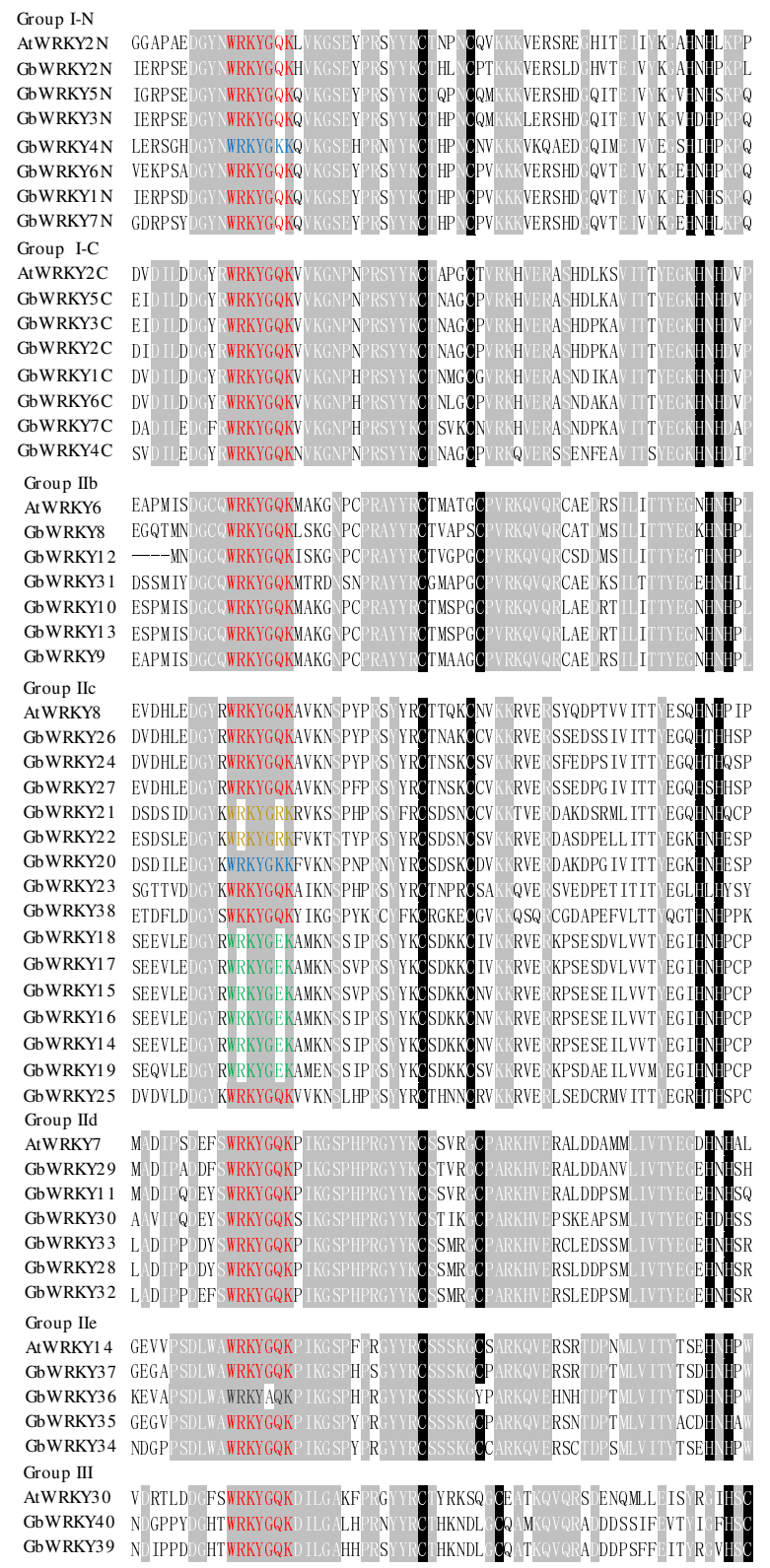

Fig. 1. Alignment of multiple GbWRKY and selected AtWRKY domain sequences. The suffix "N" or "C" indicates the N-or Cterminal WRKY domains of a specific WRKY protein. The different groups were analyzed each. The amino acids forming the zinc-finger motif are highlighted in black. The conserved WRKY amino acid signature is highlighted in red and other different colors 
Phylogenetic analysis of G. biloba WRKYs

The WRKY transcription factor phylogenetic tree (Fig. 2) was constructed by combining the WRKY transcription factor protein sequences obtained from $A$. thaliana, $H$. brasiliensis, G. arboretum, and T. chinensis var. mairei and the GbWRKY transcription factor protein sequence in $G$. biloba were identified. The phylogenetic tree showed the evident clustering of WRKY transcription factors. Among these transcription factors, groups I-N, I-C, and III all belonged to a single lineage group; group II is divided into four small branches, namely, groups IIc, $a+b, d$, and e. Rushton et al. (2015) studied the phylogenetic relationships of $W R K Y$ genes in plants and found that groups IIa and $\mathrm{b}$ were clustered on one large branch, while groups IId and e were clustered on the other major branch. This result is consistent with the phylogenetic tree constructed in $G$. biloba WD analysis. At the same time, in this phylogenetic tree, the classification of GbWRKY found in G. biloba was essentially the same as that of $A$. thaliana and $H$. brasiliensis, which verifies the correctness of GbWRKY transcription factor classification and phylogenetic tree construction in $G$. biloba individual species. This result also showed that the classification of GbWRKY transcription factors in ginkgo was completely similar to the classification of WRKY transcription factors in other species. Fig. 2 shows that WRKY transcription factors from G. biloba, A. thaliana, and other species were distributed in the branches of the evolutionary tree. This result indicated that the homology of orthologous WRKY transcription factors is higher than that the homology of paralogous ones. The gene amplification events of GbWRKY transcription factors have evolved before the differentiation of these species. Groups IIc, IIa + b, and I-C were clustered on one large branch, thereby suggesting that they may have a common origin.

In the phylogenetic tree, WRKY transcription factors clustered together may have similar functions. To determine whether the G. biloba WRKY proteins regulate the terpene trilactone synthesis, we clustered them with WRKY proteins of other plants that regulate terpene trilactone synthesis. The results showed that these proteins do not have a close relationship. These GbWRKY proteins may have other functions, or the WRKY proteins of other plants of other plants we selected may be excessively few to be representative. AtWRKY3 and AtWRKY4 in group I-N had a similar mechanism of resistance regulation against Botrytis cinereal (Lai et al., 2008). AtWRKY38 and AtWRKY62 (Kim et al., 2008c) in group III both regulated the defense mechanisms of plants against Pseudomonas syringae. Similarly, AtWRKY18 and AtWRKY60 (Chen et al., 2010) clustered in group IId in phylogenetic tree played similar functions in response to salt and osmotic stresses. AtWRKY11 and AtWRKY17 clustered together in the group IId can modulate plant defense against $P$. syringae (Journot-Catalino et al., 2006). A similar situation can be analogous to G. biloba, where the clustered GbWRKY transcription factors possessed high homology and may also have similar functions. The function of WRKY transcription factors clustered in a group from different species may also possess certain similarity.
Structural and conserved motif analysis

WRKY proteins are featured by the WD, which is a 60amino acid stretch containing a conserved amino acid sequence of WRKYGQK together with a $\mathrm{Zn}$ finger-like motif (Eulgem et al., 2000). Either one or two WDs were present in each protein. Some members of the family have Leu zippers, which contain several repeats of seven hydrophobic amino acids with Leu at every seventh position, toward the $\mathrm{N}$ terminus (Eulgem et al., 1999). Unfortunately, Leu zippers were absent in the G. biloba WRKY protein.

To fully understand the conservation and diversity of the WRKY protein domain of G. biloba, we used the online software MEME 5.0.11 for analysis. A total of 20 motifs were obtained to describe the details of the WRKY protein structure in Ginkgo (Fig. 3). As shown in Fig. 4, motifs 1, 2, and 4 corresponded to the WD distributed in almost all GbWRKY proteins. The WRKYGQK short peptide in the WRKY core motif was much conserved, and only a small number of variant WRKYGQK short peptides, such as WRKYGKK, WRKYGEK, WRKYGRK, and WRKYAQK, was found in groups I-N, IIc, and IIe. Certain group- or subgroup-specific motifs were identified as follows: motif 3 was unique to the N-terminal WDs of group I; motif 6 existed only in the WDs with GbWRKY15, GbWRKY16 and GbWRKY18, and they all belonged to group IIc; motifs $16,17,18,4,1$, and 2 were found in GbWRKY28, GbWRKY11, GbWRKY29, GbWRKY30, GBWRKY32, GBWRKY33, and AtWRKY7, and these WRKY proteins belonged to group IId; motifs 16 and 17 were only present in group IId. GbWRKY2, GbWRKY3, GbWRKY5 and GbWRKY2 proteins also had common motifs. Motifs 14, 13, and 10 were only distributed at their C-terminus, thereby indicating the possibility that these four WRKY proteins have biological function of these. The analysis of the type and number of motifs among different groups of G. biloba WRKY proteins will contribute for further study of the structure and function of WRKY proteins in G. biloba and other plants.

Exon and intron structures can also provide information in analysing phylogenetic relationships and gene function in gene families. In this study, we identified 40 GbWRKYs in combination with ginkgo genome and transcriptome databases. Among 40 GbWRKYs, 33 were identified from the genome. Therefore, we examined the exon-intron organization of $33 G b W R K Y$ genes to gain in-depth understanding of the evolution of the WRKY family in $G$. biloba. As shown in Fig. 5A and 5B, all GbWRKY genes possessed 2 (GbWRKY38)-17 (GbWRKY6) exons. Each gene possessed at least two exons, no gene only had one exon. Genes from the same group or subgroup showed similar intron structures and numbers. All group IId members possessed three exons and two introns, and all group III members possessed four exons and three introns. In summary, the similar gene structure of WRKY members in the same group and the phylogenetic analysis results, further illustrate the accuracy of the classification of the $G$. biloba WRKY gene family. 
1106

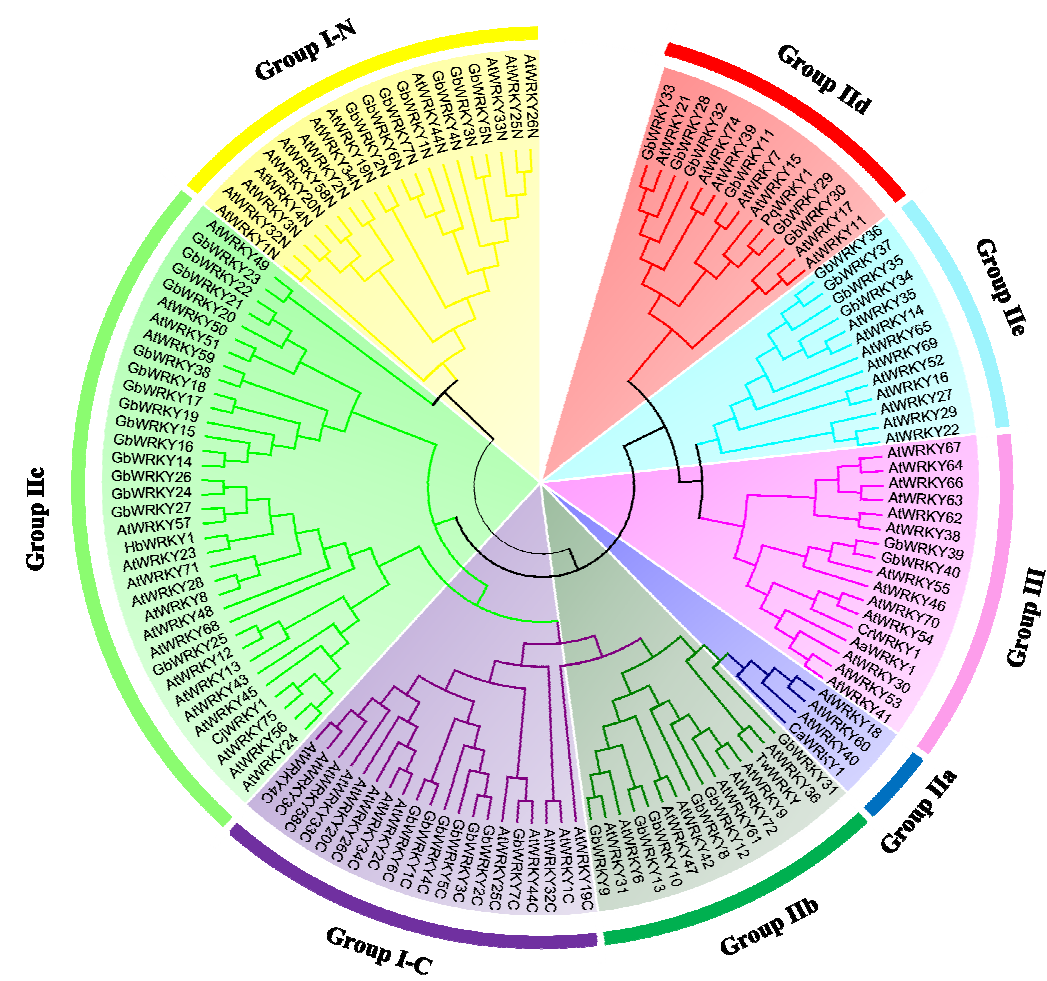

Fig. 2. Phylogenetic tree representing relationship among WRKY domains of G. biloba, Arabidopsis thaliana and other plants. The amino acid sequences of the WRKY domain of 40 GbWRKY, 71 AtWRKY proteins and 7 other plants were aligned with ClustalX and the phylogenetic tree was constructed using the neighbor-joining method in MEGA 6.0 with 1000 bootstrap replicates. Group I proteins with the suffix "N" or "C" indicates the N-terminal WRKY domains or the C-terminal WRKY domains. GI-C WRKY domain of Group I proteins (dark purple); GI-N WRKY domain of Group I proteins (yellow); group IIa proteins (dark blue); group IIb proteins (dark green); group IIc proteins (light green); group IId proteins (red); group IIe proteins(skyblue); group III proteins (roseo)

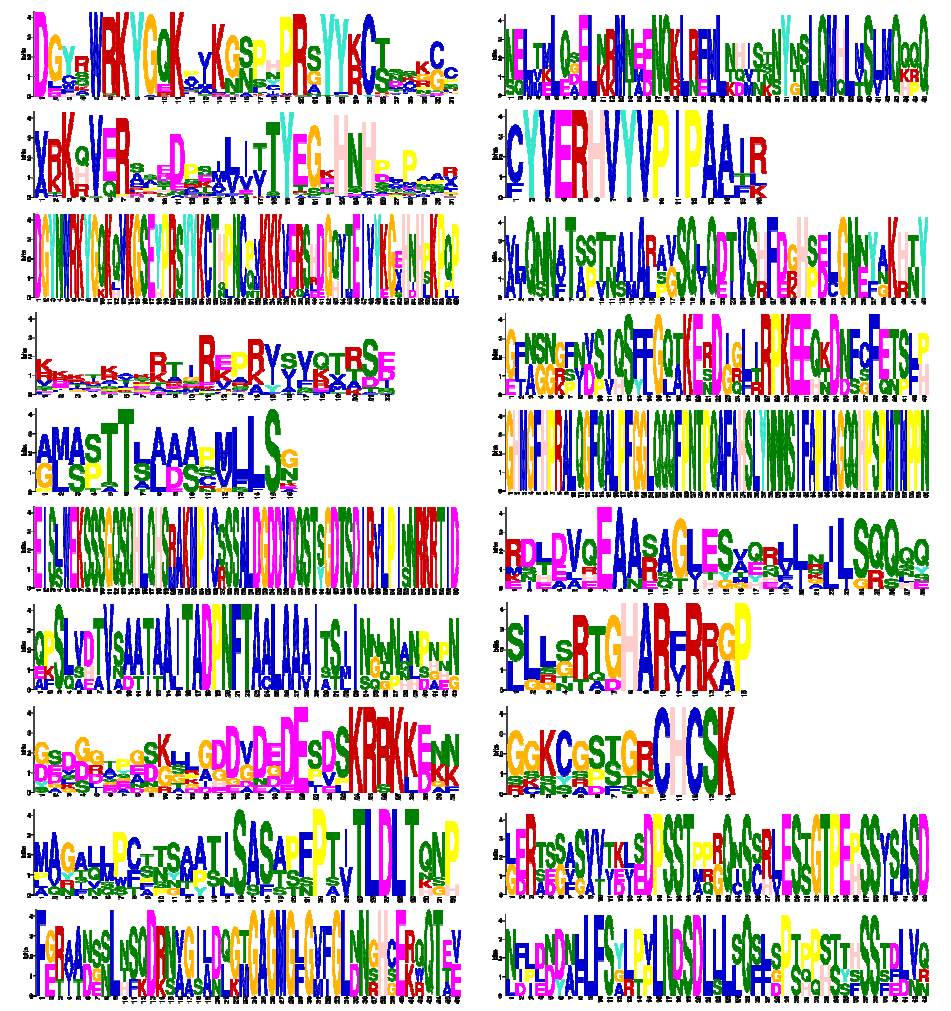

Fig. 3. Sequence information of each motif 


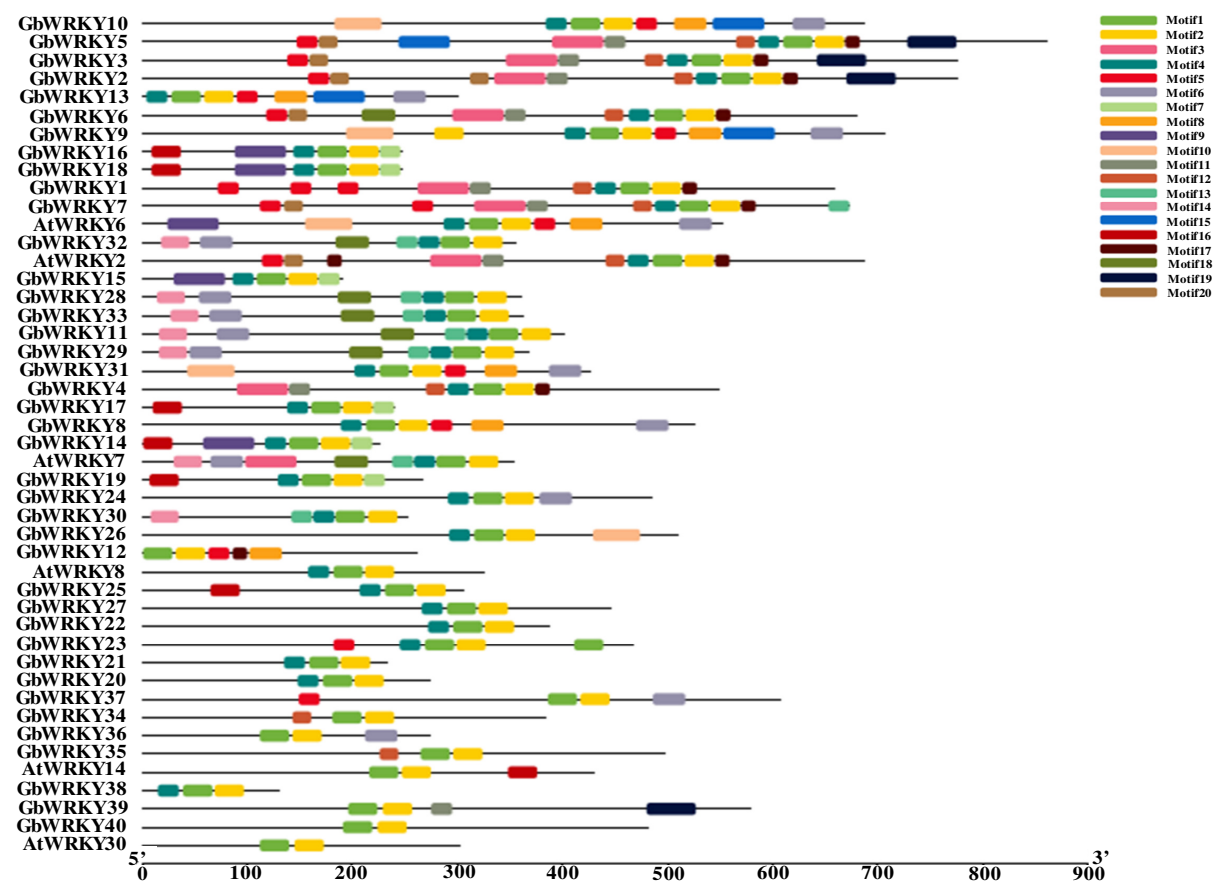

Fig. 4. Conserved motifs in WRKY protein sequences. The motif composition of 40 G. biloba WRKY proteins and 6 Arabidopsis WRKY protein is shown on the right. Different motifs are displayed in different coloured boxes, with a total of 1-20 numbers. The sequence information for each motif is provided in Table S1

(A) Phylogenetic Tree

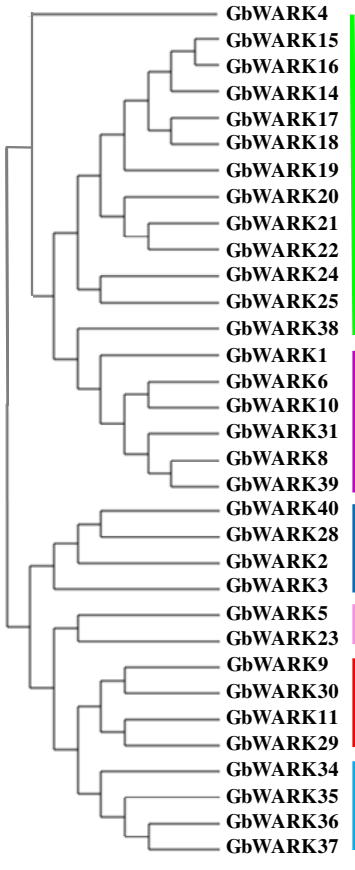

\section{(B) Gene Strusture}

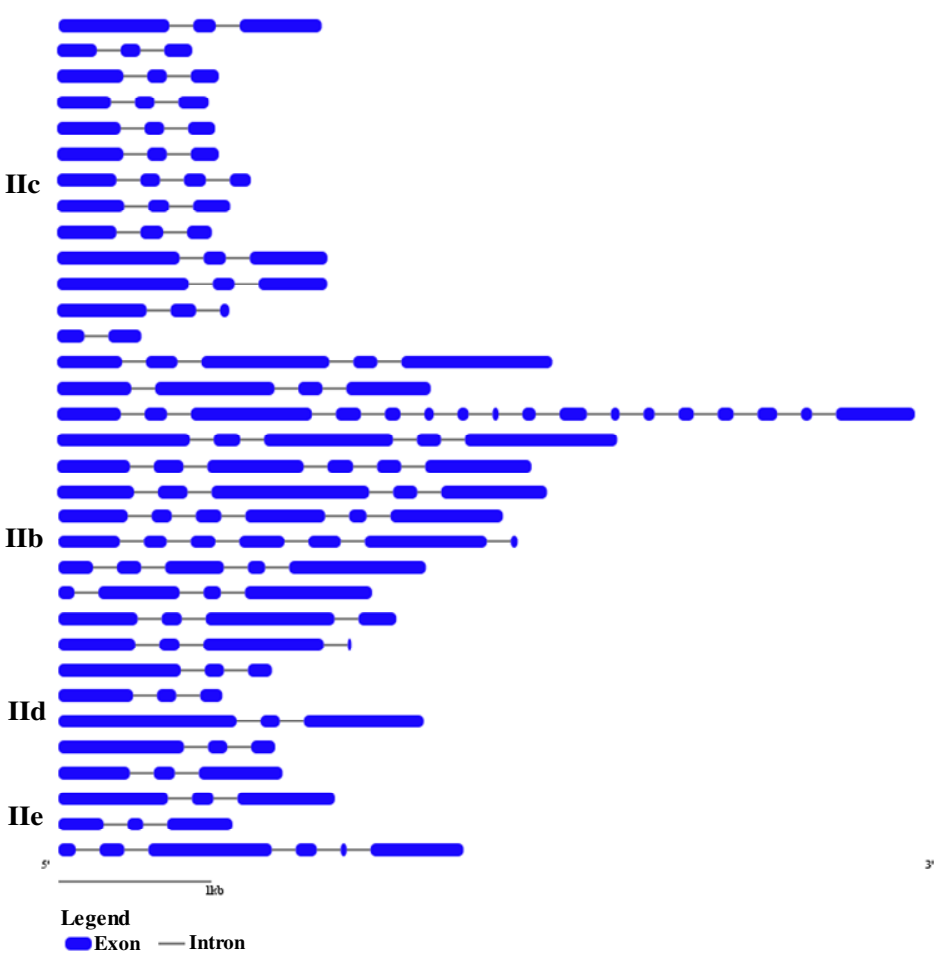

Fig. 5. Phylogenetic relationships and gene structure of conserved protein motifs in WRKY genes from G. biloba. (A) The phylogenetic tree was constructed based on the full-length sequences of G. biloba WRKY proteins using MEGA 6.0 software. (B) Intron and exon structures of WRKY genes in G. biloba. Blue boxes indicate exons; black lines indicate intron 
1108

Differential expression profiles of GbWRKY in various $G$. biloba tissues

As shown in Fig. 6, 10 GbWRKY genes were constitutively expressed in all tested $G$. biloba tissues. However, the expression levels were relatively different and showed organ specificity. The expression level of four GbWRKYs (GBWRKY7, GbWRKY15, GbWRKY31, and $G b W R K Y 5)$ were significantly higher in leaves than in other tissues. GbWRKY2 expression was the highest in male and female flowers, followed by leaves; GbWRKY29 had the highest expression in stems, followed by female flowers; $G b W R K Y 3$ and GbWRKY11 had the highest expression levels in female flowers among the tested tissues; GbWRKY23 had higher expression levels in leaves and female flowers than other tissues. GBWRKY32 had similar expression levels in leaves, stems, and female flowers but significantly higher than in roots and male flowers. Hence, GbWRKY4, GbWRKY15, GbWRKY31, and GbWRKYS are genes with leaf-specific expression; GbWRKY2 is a gene with male and female flower-specific expression; GbWRKY29 is a gene with stem-specific expression. biloba

GbWRKY expression level under stress treatments in $G$.

A time course expression analysis of the GbWRKY genes was performed under ABA, SA, ETH, MeJA, $\mathrm{NaCl}$, chilling, and heat treatments. Given that the expression of GbWRKYs has organ-specificity, to eliminate the errors caused by inconsistent materials, the same batch of $G$. biloba callus with the same growth tendency was selected as the stress material. As shown in Fig. 7A, the relative expression levels of 10 GbWRKYs were compared with the control within $72 \mathrm{~h}$ after $100 \mu \mathrm{mol} \mathrm{L} \mathrm{L}^{-1}$ ABA-treated G. biloba suspension calli, the expression of $7 G b W R K Y s$ (i.e., GbWRKY2, GbWRKY29, GBWRKY7, GbWRKY3, GbWRKY11, GbWRKY15, and GbWRKYS) were upregulated by ABA-induced. The remaining three GbWRKYs showed downregulated expression. Among these genes, GbWRKY29 can respond quickly to ABA induction. The expression level of the gene reached its maximum at $3 \mathrm{~h}$ after treatment and was significantly higher than that of the control within $48 \mathrm{~h}$ after treatment. The expression level decreased to below the control level at $72 \mathrm{~h}$ after treatment. The gene expression levels of GbWRKY2, GBWRKY7, GbWRKY11, GbWRKY15, and GbWRKYS reached the maximum within 6-24 h after treatment. The expression level of GbWRKY3 decreased rapidly at $3 \mathrm{~h}$ after treatment, rapidly increased to a maximum at $6 \mathrm{~h}$ after treatment, and then rapidly decreased below its expression level in the control group. The gene expression levels of GbWRKY23, GbWRKY31, and $G B W R K Y 32$ during the entire treatment period were significantly lower those in the control. The results indicated that 7 of the $10 \mathrm{GbWRKY}$ transcription factors were induced by $\mathrm{ABA}$, and 3 genes were inhibited by $\mathrm{ABA}$.

As shown in Fig. $7 \mathrm{~B}$, the relative expression of 10 GbWRKYs was determined within $72 \mathrm{~h}$ after callus induction with $100 \mu \mathrm{mol} \mathrm{L}^{-1}$ SA. 6 GbWRKYs (GbWRKY2, GbWRKY3, GbWRKY15, GbWRKY31,
GBWRKY32, and GbWRKYS) showed increased expression level compared with the control. After reaching the maximum, the expression gradually decreased below the control level as the treatment time increased. The expression levels of the remaining $4 G b W R K Y s$ decreased at the early stage of treatment but rapidly increased within 24$48 \mathrm{~h}$ and reached a maximum value at $24 \mathrm{~h}$. At the end of the experiment, the expression level decreased below the control level at $72 \mathrm{~h}$ after treatment. This result indicated that $10 \mathrm{GbWRKY}$ transcription factors were all induced by SA, but two different patterns of induction response were observed.

As shown in Fig. 7C, seven GbWRKYs (i.e., GbWRKY29, GBWRKY7, GbWRKY3, GbWRKY11, GbWRKY15, GbWRKY23, and GbWRKY5) were observed after the treatment of $G$. biloba callus with $40 \mu \mathrm{mol}$ $\mathrm{L}^{-1}$ ETH. The expression levels at 3-12 h of treatment were significantly higher than that of the control and decreased to the control level or lower at $24-72 \mathrm{~h}$ after treatment. The expression levels of the remaining three genes decreased at the early stage of treatment, suddenly reached the maximum at $12 \mathrm{~h}$, and then quickly dropped below the control level. Hence, $10 \mathrm{GbWRKY}$ transcription factors were induced by ETH, but two different patterns of induction response were observed.

As shown in Fig. 7D, after treatment with $G$. biloba callus with $100 \mu \mathrm{mol} \mathrm{L} \mathrm{L}^{-1} \mathrm{MeJA}$, the expression of 8 GbWRKYs (GbWRKY29, GBWRKY7, GbWRKY3, GbWRKY11, GbWRKY23, GbWRKY31, GBWRKY32, and $G b W R K Y 5)$ was downregulated compared with that of the control. Among these genes, GbWRKY23, $G b W R K Y 31$, and GBWRKY32 were strongly inhibited by $\mathrm{MeJA}$; at $3 \mathrm{~h}$ after treatment, the expression levels of $G b W R K Y 15$ and GbWRKY2 rapidly increased to their maximum values and then rapidly decreased below the control level. The results showed that GbWRKY15 and $G b W R K Y 2$ rapidly responded to MeJA induction in the 10 GbWRKY transcription factors, and the expression of the remaining $8 \mathrm{GbWRKYs}$ were inhibited by MeJA.

As shown in Fig. 7E, $200 \mu \mathrm{mol} \mathrm{L}{ }^{-1} \mathrm{NaCl}$ was used to treat $G$. biloba callus for $72 \mathrm{~h}$, and the expression levels of 10 $G b W R K Y s$ were analyzed. The results showed that the expression levels of four GbWRKYs (i.e., GbWRKY29, GBWRKY7, GbWRKY3, and GbWRKY11) were downregulated. The expression levels of the remaining 6 $G b W R K Y s$ at $3 \mathrm{~h}$ after treatment increased rapidly to the maximum and then quickly decreased below the control level. This result indicated that the expression of four GbWRKYs of the ten G. biloba WRKY transcription factors was inhibited by high salinity, and six GbWRKYs were induced by high salinity.

As shown in Fig. 7F, G. biloba callus was treated with low temperature for $72 \mathrm{~h}$ to analyze the expression levels of $10 G b W R K Y$ genes. The expression levels of the majority of the genes were lower than the control level, thereby indicating that the expression of these genes was inhibited by chilling treatment. Meanwhile, the expression of GbWRKY32 at the initial stage under low temperature stress initially reached the lowest level, gradually increased, reached the maximum within $12-24 \mathrm{~h}$, and then decreased 
rapidly but remained above the control level before the end of the experiment. The GbWRKY32 expression was induced by low temperature. The relative expression levels of $10 G b W R K Y s$ were all downregulated compared with the control within $72 \mathrm{~h}$ after $G$. biloba callus heat treatment (Fig. 7G). The results showed that $10 \mathrm{G}$. biloba WRKY transcription factor genes were all expressed at high temperature.
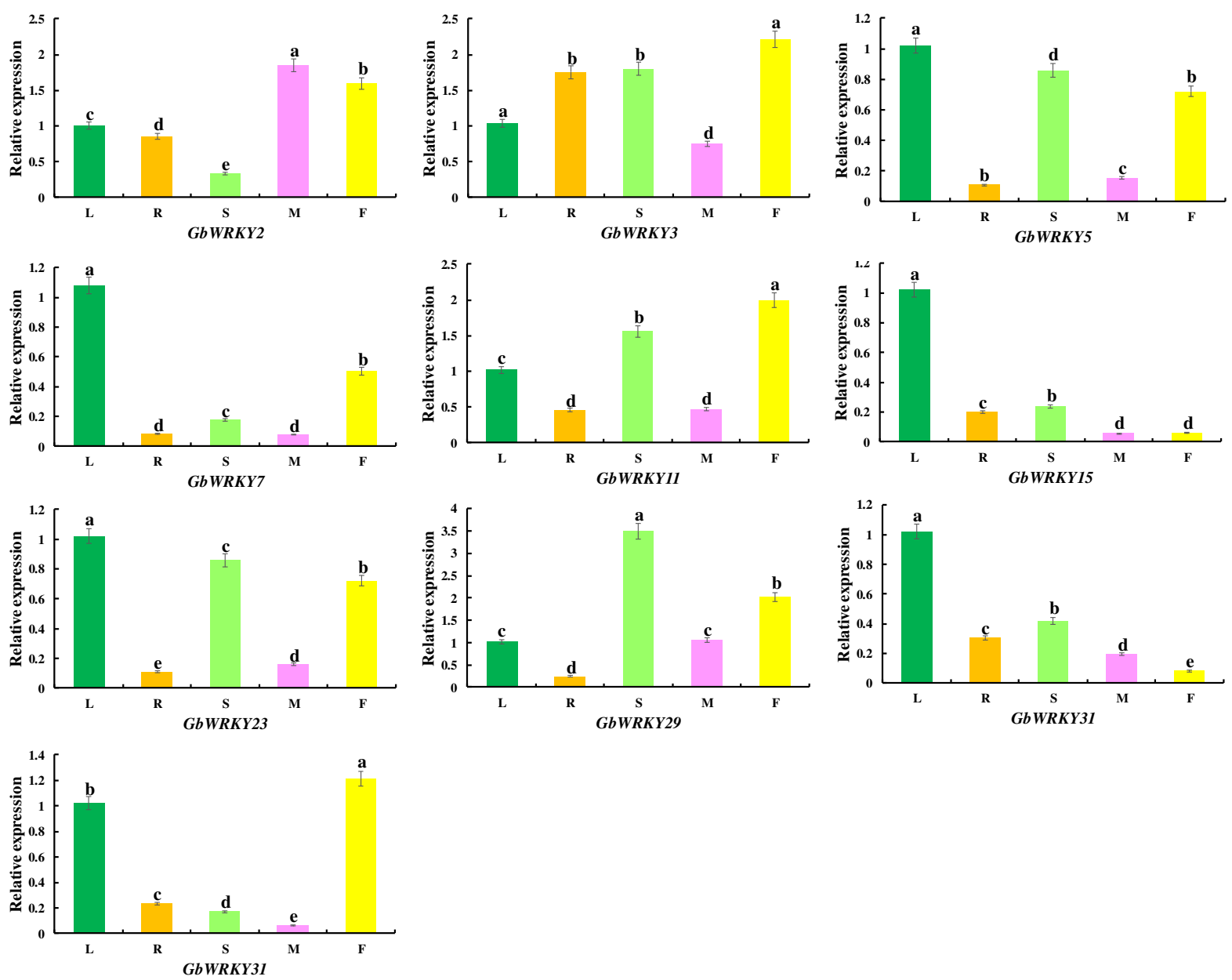

Fig. 6. Expression profiles of $G b W R K Y$ in G. biloba different tissue. L: leaf; R: root; S: stem; M: male flower; F: female flower. The gene expression level of $G b W R K Y$ in leaf was set to 1 . Data are mean \pm SD from triplicate experiments $(\mathrm{n}=3)$ 
1110
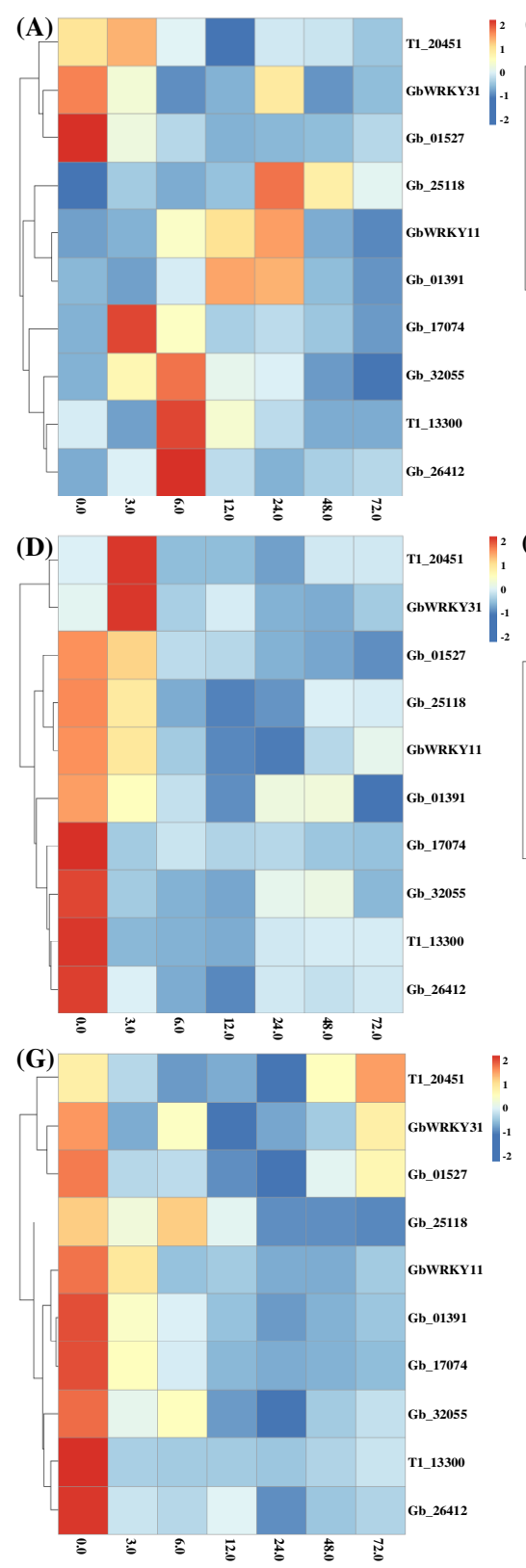
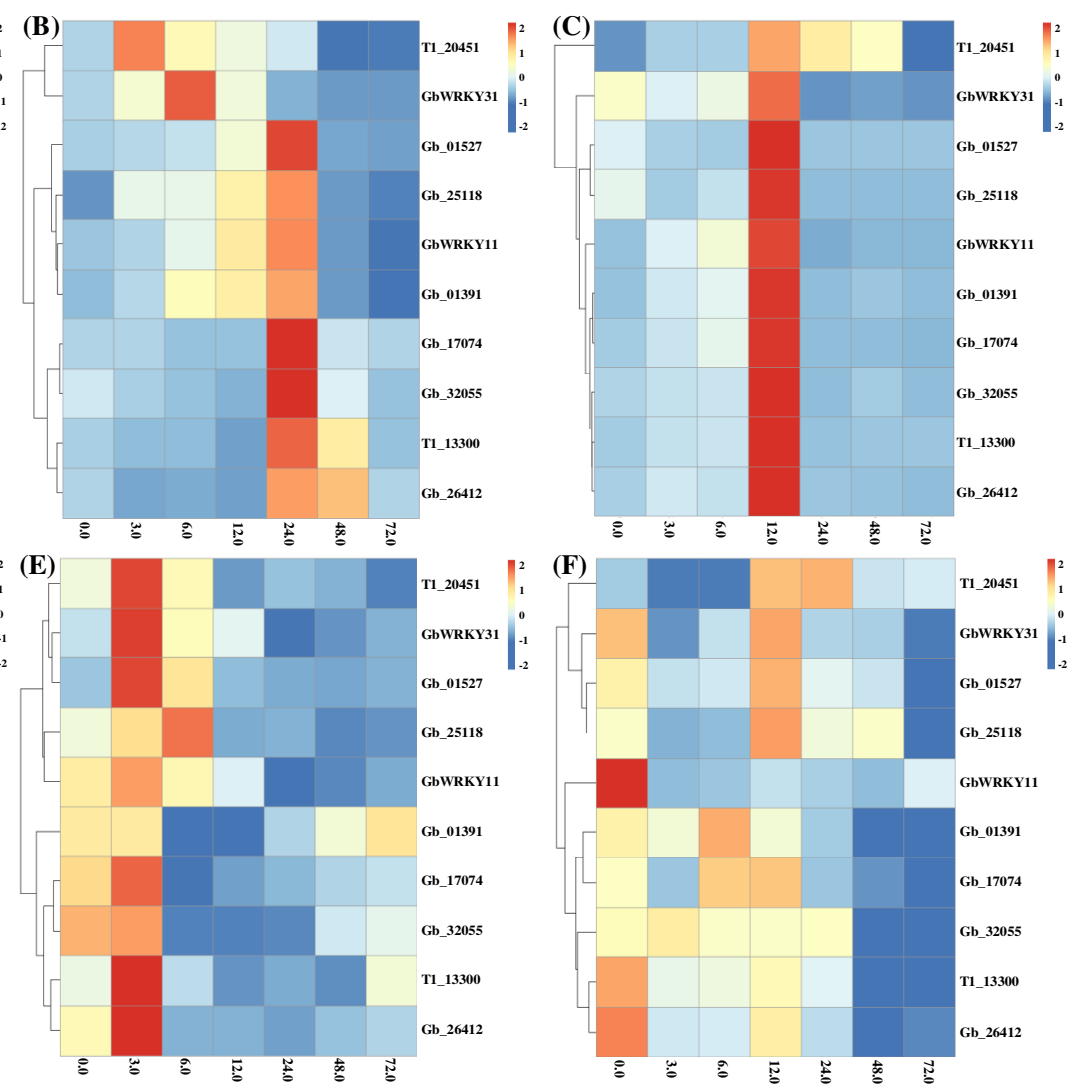

Fig. 7. Heatmap analysis of GbWRKY expression level in G. biloba under the induction of ABA, SA, ETH, MeJA, Salt, Cold, Heat. (A) Expression profiles of GbWRKY in response to ABA treatment; (B) Expression profiles of $G b W R K Y$ in response to SA treatment; (C) Expression profiles of GbWRKY in response to ETH treatment; (D) Expression profiles of GbWRKY in response to MeJA treatment; (E) Expression profiles of GbWRKY in response to salt treatment; (F) Expression profiles of GbWRKY in response to cold treatment; (G) Expression profiles of GbWRKY in response to heat treatment. Each column represents the time of stress treatment, whereas each row represents a gene. Expression differences are observed in different colors. The time of the stress treatment is shown at the top. The expression levels were normalized to GbGAPDH gene and shown as $\log 10$ 


\section{Discussion}

The first plant WRKY gene, that is, SWEET POTATO FACTORI, was cloned from sweet potato on the basis of its ability to bind specifically to the SP8 DNA sequence motif TTGACCT, which is known as the $\mathrm{W}$ box (Ishiguro and Nakamura, 1994). Subsequently, a large number of plant WRKY proteins was investigated in numerous plants. To date, 14549 WRKY sequences are available in the plant TF database (http://planttfdb.cbi.pku.edu.cn/). Since the release of a large number of publicly available sequences and even complete whole-genome sequences in some plants, the genome-wide analyses of the $W R K Y$ gene family have been performed. A total of $90 W R K Y$ family members were observed in A. thaliana, 104 in Oryza barthii, 161 in Zea mays, 50 in Picea abies (Jin et al., 2017), and 21 in Pinus taeda. To date, Glycine max has the largest number of WRKY family members among the sequenced plants (Yin et al., 2013). The variation in the number of WRKY family members from different plant species may be due to genomic duplication events or environmental adaption, thereby indicating the specificity after divergence from the last come ancestor (Liu et al., 2017).

With the increasing number of identified and discovered WRKY genes, group I and II $\mathrm{a}+\mathrm{b}$ separate hypotheses have been proposed. The former indicates that all WRKY genes evolved from the C-terminal domain of group I, whereas the latter claims that groups IIa and b genes may have evolved from a single domain ancestral algal WRKY gene (Rinerson et al., 2015). The analysis of the $W R K Y$ genes of the complete genomic sequence of several flowering plants divided WRKY transcription factors into the seven major subfamilies, namely, groups I, IIa, IIb, IIc, IId, IIe, and III (Eulgem et al., 2000). On the basis of the evolutionary analysis of WDs, conserved domains, and intron locations, Zhang and Wang (2000) proposed another model that classifies WRKY proteins into five groups, as follows: groups I, IIa + b, IIc, IId + e, and III. They divided WRKY transcription factors into two categories on the basis of the insertion site of introns (Zhang and Wang, 2000). The first class includes the WRKY gene with an intron of type $R$, whose splice site is between the two Gs arginine in codon AGG. The other class includes the V-type intron WRKY, where the splice site is located in front of the valine codon. WRKY transcription factors can activate or inhibit transcription in physiological processes (Xie et al., 2005). In addition to WDs and $\mathrm{Zn}$ finger structures, most WRKY transcription factors have nuclear localization signals, serine/threonine rich regions, glutamine-rich regions, proline-rich regions, kinase domain, and TIR-NBS-LRR. The presence of these structures makes WRKY transcription factors possess different transcriptional regulatory functions (Zhang and Wang, 2000). In our phylogenetic tree, the grouping of GbWRKY is consistent with those of the previous studies, where groups II $a$ and $b$ are clustered together to form II $a+b$ and closely related to group I-C. The relationship among groups III, IIe, and IId is also closer.

GbWRKY genes are commonly expressed in various tissues, but the expression levels are relatively different and possessed organ specificity. GBWRKY7, GbWRKY15,
GbWRKY31, and GbWRKYS genes were specifically expressed in leaves; GbWRKY3 and GbWRKY11 genes were highly expressed in female flowers; GbWRKY29 was highly expressed in stems; and GbWRKY2 was highly expressed in male and female flowers. Genes that are specifically expressed in a particular tissue may have important regulatory effects on the development and metabolism of the tissues in which they are located.

WD binds to a W-box (TTGACC/T) in the promoters of the target genes (Rushton et al., 1996; Ciolkowski et al., 2008). W-Boxes can be found in the promoters of the systemic acquired resistance-related genes, including isochorismate synthase 1 , non-expressor of $P R$ genes 1 , and pathogenesis-related 1 (Zheng et al., 2013). Determining whether a promoter contains multiple W-boxes and even contains motif clusters occasionally is difficult. W-Boxes are also found in the promoter of WRKY genes, thereby suggesting a potentially strong transcriptional networking among WRKY proteins (Llorca et al., 2014). The binding of WRKY proteins to W-boxes is a feature of both biotic and abiotic stress responses. A total of $26 A t W R K Y$ genes that responded to salt stress and upregulated expression were observed in $A$. thaliana (Jiang and Deyholos, 2006). Out of $64 G m W R K Y$ genes, 25 changed their expression levels in response to at least one abiotic stress (Zhou et al., 2008). A total of 49 AtWRKY genes also responded to bacterial infection and SA induction (Ramamoorthy et al., 2008). Our study found that the tested 10 GbWRKY genes can rapidly change their expression levels under stress. The expression of most genes was upregulated under SA, ETH, $\mathrm{ABA}$, and high salt treatments and downregulated due to MeJA, chilling, and heat treatments. Each gene responded to at least one stress induction. Some GbWRKY genes rapidly responded to stress at the early stage of stress induction, and the expression level rapidly increased and then decreased sharply, thereby showing a rapid and transient response (e.g., GbWRKY2, GbWRKY15, GbWRKY23, GbWRKY23, GBWRKY32, and GbWRKY5 under salt stress; GbWRKY2 and GbWRKY15 under MeJA stress). Some $G b W R K Y$ genes also played a role in late stress response (e.g., GBWRKY32 in cold stress; GbWRKY29, GBWRKY7, GbWRKY11, and GbWRKY23 in SA stress). Even a part of GbWRKY was continuously expressed during stress (e.g., GbWRKY31 under cold stress and GbWRKY 15 under SA stress). In other plants, there are also related research reports. For example, the OsWRKY11 of rice can activate the expression of some genes related to raffinose synthesis to promote the accumulation of raffinose in plants, thereby improving the drought resistance of rice. The expression of the OsWRKYI1 gene was also induced by high temperature, and the expression of OsWRKYII gene initiated by HSP101 promoter increased the heat tolerance of rice (Wu et al., 2009). WRKY protein can also directly regulate the expression of drought-resistant genes and improve the drought resistance of plants. STZ encodes a drought-tolerant protein with a Cys $2 / \mathrm{His} 2$ zinc finger structure. Its expression level is induced by drought, high salt, cold damage and ABA treatment. It can increase the drought resistance of plants when overexpressed in Arabidopsis and rice (Sakamoto et al., 2004). The 
1112

AtWRKY39 gene of Arabidopsis can promote high temperature stress response through signaling pathways mediated by SA and JA ( $\mathrm{Li}$ et al., 2010). In addition to directly regulating the expression pattern of the target gene, some WRKY proteins indirectly regulate the expression level of the functional gene by interacting with other transcription factors. The TcWRKY53 gene of Thlaspi caerulescens encodes a negative regulator involved in osmotic stress, and its expression is strongly induced by drought, $\mathrm{NaCl}$ and low temperature (Wei et al., 2008).

Most of the genes in eukaryotes are composed of exons and introns. Exons are mainly responsible for encoding proteins, while introns are characterized by self-splicing. By selecting splicing, a gene can produce different mature mRNAs, which can be translated into functionally distinct proteins, and even produce distinct proteins, sometimes the function is even the opposite (Howe and Ares, 1997). This regulatory mechanism allows certain genes to produce specific proteins in different cell tissues or at different stages of development to meet the metabolic needs of the organism (Blencowe et al., 2006). In this study, we analyzed the gene structure of different GbWRKY genes, different genes have different numbers of introns and exons, and the selected 10 GbWRKY genes have tissue expression specificity, which may be determined by gene structure. At present, regulatory elements of gene expression have been found in introns of many genes, and some genes have introns in response to stress response elements to assist in the inducible expression of genes (Balvay et al., 1992). Responding to stress is a complex process. Therefore, whether the induced expression of GbWRKY under different stress treatments is caused by the response to stress response elements in its introns requires further verification. The above-mentioned results indicated that the GbWRKY genes have a relatively complex expression pattern, thereby suggesting that the GbWRKY transcription factors have complex and variable regulation during the stress resistance of $G$. biloba to adapt to this series of complex physiological changes. Therefore, in order to thoroughly understand the regulation mechanism of the GbWRKY gene, a large amount of research is needed in the later stage.

\section{Conclusions}

In our study, 40 GbWRKYs were identified and classified into groups I (groups I-N and -C), II (groups IIa, $\mathrm{b}, \mathrm{c}, \mathrm{d}$, and $\mathrm{e}$ ), and III, which include 12,26 , and 2 GbWRKY genes, respectively. The WRKYGQK core motif was highly conserved, with only a few common variants found in group I-N and II-c (WRKYGKK, WRKYGEK, and WRKYGRK). Zn finger structures differed remarkably in different GbWRKY groups. The sequence of the $\mathrm{Zn}$ finger structure of group I-N was C-X4-C-X22-H-X1-H. For group I-C and IIc, the sequence was C-X4-C-X23-H$\mathrm{X} 1-\mathrm{H}$. For groups IIb, d, and e, the sequence was C-X5-C$\mathrm{X} 23-\mathrm{H}-\mathrm{X} 1-\mathrm{H}$. Through the qRT-PCR technique, 10 candidate GbWRKY genes were randomly selected for tissue expression. The results showed that these genes showed differential expression patterns in various tissues with organ specificity. Some genes had similar expression levels; hence, they may have similar functions. The
GbWRKY gene expression levels in $G$. biloba callus under different elicitor treatments verified the crucial roles of the GbWRKY genes in stress response. However, whether all WRKY transcription factors play a role in plant physiology and whether the function is repeated are still unclear. The mechanism underlying the crosstalk between the WRKY transcription factor self-regulation pattern and the signal transduction pathway involving WRKY transcription factors are also unclear, and further research is needed. Our research information will aid in revealing the role of the WRKR transcription factors in plant stress responses and will be useful for further study of the function of the WRKY genes. However, in-depth research is needed to determine the function and role of each ginkgo $W R K Y$ gene.

\section{Acknowledgements}

This work was supported by the National Science Foundation of China (No. 31370680).

\section{Conflict of Interest}

The authors declare that there are no conflicts of interest related to this article.

\section{References}

Agarwal P, Reddy MP, Chikara J (2011). WRKY: its structure, evolutionary relationship, DNA-binding selectivity, role in stress tolerance and development of plants. Molecular Biology Reports 38(6):3883-3896.

Balvay L, Libri D, Gallego M, Fiszman MY (1992). Intronic sequence with both negative and positive effects on the regulation of alternative transcripts of the chicken beta tropomyosin transcripts. Nucleic Acids Research 20(15):3987-3992.

Blencowe BJ (2006). Alternative splicing: new insights from gobal analyses. Cell 126(1):37-47.

Chen H, Lai Z, Shi J, Yong X, Chen Z, Xu X (2010). Roles of Arabidopsis WRKY18, WRKY40 and WRKY60 transcription factors in plant responses to abscisic acid and abiotic stress. BMC Plant Biology 10(1):443-462.

Chen L, Tong H, Wang M, Zhu J, Zi J, Song L, Yu R (2015). Effect of enzyme inhibitors on terpene trilactones biosynthesis and gene expression profiling in Ginkgo biloba cultured cells. Natural Product Communications 10(12):2033-2035.

Chen Q, Yan J, Meng X, Xu F, Zhang W, Liao Y, Qu J (2017). Molecular cloning, characterization, and functional analysis of acetyl-CoA Cacetyltransferase and mevalonate kinase genes involved in terpene trilactone biosynthesis from Ginkgo biloba. Molecules 22(1):74.

Cheng SY, Li LL, Yuan HH, Xu F, Cheng H (2015). Molecular cloning and characterization of GbMECT and GbMECP gene promoters from Ginkgo biloba. Genetics and Molecular Research 14(4):1511215122.

Ciolkowski I, Wanke D, Birkenbihl RP, Somssich IE (2008). Studies on dna-binding selectivity of WRKY transcription factors lend structural clues into WRKY-domain function. Plant Molecular Biology 68(12):81-92. 
DaiX, Wang Y,Zhang WH(2016). OsWRKY74, a WRKY transcription factor, modulates tolerance to phosphate starvation in rice. Journal of Experimental Botany 67(3):947-960.

Du S, Sang Y, Liu X, Xing S, Li J, Tang H, Sun L (2016). Transcriptome profile analysis from different sex types of Ginkgo biloba L. Frontiers in Plant Science 7:871.

Eulgem T, Rushton PJ, Robatzek S, Somssich IE (2000). The WRKY superfamily of plant transcription factors. Trends in Plant Science 5(5):199-206.

Eulgem T, Rushton PJ, Schmelzer E, Hahlbrock K, Somssich IE (1999). Early nuclear events in plant defense signaling: rapid gene activation by WRKY transcription factors. EMBO Journal 18(17):4689-4699.

Finn RD, Coggill P, Eberhardt RF, Eddy SR, Mistry J, Mitchell AL, ... Bateman A (2016). The Pfam protein families database: towards a more sustainablefuture. Nucleic Acids Research 44:D279.

Gong Y, Liao Z, Guo B, Sun X, Tang K (2006). Molecular cloning and expression profile analysis of Ginkgo biloba DXS gene encoding 1-deoxyd-xylulose 5-phosphate synthase, the first committed enzyme of the 2-cmethyl-d-erythritol 4-phosphate pathway. Planta Medica 72(04):329335.

Gong YF, Liao ZH, Chen M, ZOU K, Gou L, Tan Q, ... Tang K (2005). Molecular cloning and characterization of a 1-deoxy-D-xylulose Sphosphate reductoisomerase gene from Ginkgo biloba. DNA Sequence 16(2):111-120.

Guan R, Zhao Y, Zhang H, Fan G, Liu X, Zhou W, ... Liang X (2016). Draft genome of the living fossil Ginkgo biloba. Gigascience 5(1): 49.

Guo AY,Zhu QH, Chen X, LuoJC (2007). GSDS: agene structure display server.Hereditas 29(8):1023-1026.

Han J, Wang H, Lundgren A, Brodelius PE (2014). Effects of overexpression of Aaurkyl on artemisinin biosynthesis in transgenic Artemisia annua plants. Phytochemistry 102:89-96.

Han S, Wu Z, Jin Y, Yang W, Shi H (2005). RNA-Seq analysis for transcriptome assembly, gene identification, and SSR mining in ginkgo ( Ginkgobiloba L.). Tree Genetics and Genomes 11(3):37.

He B, Gu Y, Xu M, WangJ, Cao F, Xu LA (2015). Transcriptome analysis of Ginkgo biloba kernels. Frontiers in Plant Science 6:819.

Howe KJ, Ares M (1997). Intron self-complementarity enforces exon inclusion in a yeast pre-mRNA. Proceedings of the National Academy ofSciences 94(23):12467-12472.

Ishiguro S, Nakamura K (1994). Characterization of a cDNA encoding a novel DNA-binding protein, SPF1, that recognizes SP8 sequences in the $5^{\prime}$ upstream regions of genes coding for sporamin and $\beta$-amylase from sweet potato. Molecular and General Genetics 244(6):563-571.

Jiang Y, Deyholos MK (2006). Comprehensive transcriptional profiling of $\mathrm{NaCl}$-stressed Arabidopsis roots reveals novel classes of responsive genes. BMC Plant Biology 6(1):25.

Jin J, Tian F, Yang DC, Meng YQ, Kong L, ... Gao G (2017). Plant TFDB 4.0: toward a central hub for transcription factors and regulatory interactions in plants. Nucleic Acids Research 45:D1040-D1045.

Journot-Catalino N, Somssich IE, Roby D, Kroj T (2006). The transcription factors WRKY11 and WRKY17 act as negative regulators of basal resistance in Arabidopsis thaliana. The Plant Cell 18(11):3289-3302.
Kang MK, Nargis S, Kim SM, Kim SU (2013). Distinct expression patterns of two Ginkgo biloba 1-hydroxy-2-methyl-2-(E)-butenyl-4diphosphate reductase/isopentenyl diphospahte synthase (HDR/IDS) promoters in Arabidopsis model. Plant Physiology and Biochemistry 62:47-53.

Kim JH, Lee KI, Chang YJ, Kim SU (2012). Developmental pattern of Ginkgo biloba levopimaradiene synthase (GbLPS) as probed by promoter analysis in Arabidopsis thaliana. Plant Cell Reports 31(6):1119-1127.

Kim SM, Kuzuyama T, Chang YJ, Song KS, Kim SU (2006a). Identification of class 21-deoxy-D-xylulose 5-phosphate synthase and 1deoxy-D-xylulose 5-phosphate reductoisomerase genes from Ginkgo biloba and their transcription in embryo culture with respect to ginkgolide biosynthesis. Planta Medica 72(03):234240.

Kim SM, Kuzuyama T, Chang YJ, Kwon HJ, Kim SU (2006b). Cloning and functional characterization of 2-C-methyl-D-erythritol 4 phosphate cytidyltransferase (GbMECT) gene from Ginkgo biloba. Phytochemistry 67(14):1435-1441.

Kim SM, Kuzuyama T, Chang YJ, Kim SU (2006c). Cloning and characterization of 2-C-methyl-D-erythritol 2, 4-cyclodiphosphate synthase (MECS) gene from Ginkgo biloba. Plant Cell Reports 25(8):829-835.

Kim SM, Kim YB, Kuzuyama T, SU Kim (2008a). Two copies of 4 (cytidine 5'-diphospho)-2-C-methyl-d-erythritol kinase (CMK) gene in Ginkgo biloba: molecular cloning and functional characterization. Planta 228(6):941-950.

Kim SM, Kuzuyama T, Kobayashi A, Sando T, Chang YJ, Kim SU (2008b). 1-Hydroxy-2-methyl-2-(E)-butenyl 4-diphosphate reductase (IDS) is encoded by multicopy genes in gymnosperms Ginkgo biloba and Pinustaeda. Planta 227(2):287-298.

Kim KC, Lai Z, Fan B, Chen Z (2008c). Arabidopsis WRKY38 and WRKY62 transcription factors interact with histone deacetylase 19 in basal defense. The Plant Cell 20(9):2357-2371.

Kim SM, Kim SU (2009). Characterization of 1-hydroxy-2-methyl-2-(E)butenyl-4-diphosphate synthase (HDS) gene from Ginkgo biloba. Molecular Biology Reports 37(2):973-979.

Lai Z, Vinod K, Zheng Z, Fan B, Chen Z (2008). Roles of Arabidopsis WRKY3 and WRKY4 transcription factors in plant responses to pathogens. BMC Plant Biology 8(1):68.

Letunic I, Doerks T, Bork P (2015). SMART: recent updates, new developments and status in 2015. Nucleic Acids Research 43(D1):D257-D260.

LiJ, Brader G, Palva ET (2004). The WRKY70 transcription factor: a node of convergence for jasmonate-mediated and salicylate-mediated signals in plant defense. The Plant Cell 16(2):319-331.

LiLQ, HuangLP, Pan G, Liu L, Wang XY,Lu LM (2017). Identifying the genes regulated by AtWRKY6 using comparative transcript and proteomic analysis under phosphorus deficiency. International Journal of MolecularSciences 18(5):1046.

LiS, Zhou X, Chen L, Huang W, Yu D (2010). Functional characterization of arabidopsis thaliana WRKY39 in heat stress. Molecules and Cells $29(5): 475-483$. 
1114

Li XQ, Ye JB, Wang XH, Zhang WW, Xu F (2016). Molecular Cloning and sequence analysis of GbWRKY31, a novel transcription factor gene from Ginkgo biloba. International Journal of Current Research in Bioscience and Plant Biology 3(7):90-94.

Liao Y, Xu F, Huang X, Zhang W, Cheng H, Li L, ... Shen Y (2015a). Promoter analysis and transcriptional profiling of Ginkgo biloba 3hydroxy-3-methylglutaryl coenzyme a reductase $(G b H M G R)$ gene in abiotic stress responses. Notulae Botanicae Horti Agrobotanici ClujNapoca 43(1):25-34.

Liao Y, Xu F, Huang X, Zhang W, ChengH, Wang X, ... Shen Y,(2015b). Characterization and transcriptional profiling of Ginkgo biloba mevalonate diphosphate decarboxylase gene $(G b M V D)$ promoter towards light and exogenous hormone treatments. Plant Molecular Biology Reporter 34(3):566-581.

Liao YL, Shen YB, Chang J, Zhang WW, Cheng SY, Xu F (2015c). Isolation, expression, and promoter analysis of GbWRKY2: a novel transcription factor gene from Ginkgo biloba. International Journal of Genomics 2015(6):1-17.

Liao YL, Xu F, Zang WW, Cheng SY, Shen YB, ChangJ (2016). Cloning, characterization and expression analysis of GbWRKY11, a novel transcription factor gene in Ginkgo biloba. International Journal of Agriculture and Biology 18(1):18149596.

Liao Z, Chen M, GongY, Guo L, Tan Q, FengX, ... TangK(2004). A new geranylgeranyl diphosphate synthase gene from Ginkgo biloba, which intermediates the biosynthesis of the key precursor for ginkgolides. DNA Sequence 15(2):153-158.

Lin X, Zhang J, Li Y, Luo H, Wu Q, Sun C,... Chen S (2011). Functional genomics of a living fossil tree, Ginkgo, based on next-generation sequencing technology. Physiologia Plantarum 143(3):207-218.

Liu QN, Liu Y, Xin ZZ, Zhang DZ, GeBM, Yang RP, ... Zhou CL (2017). Genome-wide identification and characterization of the WRKY gene family in potato (Solanum tuberosum). Biochemical Systematics and Ecology 71:212-218.

Llorca CM, Potschin M,Zentgraf U (2014).bZIPs and WRKYs: two large transcription factor families executing two different functional strategies. Frontiers in Plant Science 5:169.

Lu J, Wu W, Cao S, Zhao H, Zeng H, Lin L, ... Tang K(2008). Molecular cloning and characterization of 1-hydroxy-2-methyl-2-(E)-butenyl-4 diphosphate reductase gene from Ginkgo biloba. Molecular Biology Reports 35(3):413-420.

Luo DL, Ba LJ, Shan W, Kuang JF, Lu WJ, Chen JY (2017). Involvement of WRKY transcription factors in abscisic-acid-induced cold tolerance of banana fruit. Journal of Agricultural and Food Chemistry 65(18):3627-3635.

Pan L, Ren L, Chen F, Feng Y, Luo Y (2016). Antifeedant activity of Ginkgo biloba secondary metabolites against Hyphantria cunea larvae: mechanisms and applications. PLoS One 11(5):e0155682.

Pang Y, Shen GA, Bergès T, Cardier H, Wu W, Sun X, Tang K (2006). Molecular cloning characterization and heterologous expression in Saccharomyces cerevisiae of a mevalonate diphosphate decarboxylase cDNA from Ginkgo biloba. Physiologia Plantarum 127(1):19-27.

Potschin M, Schlienger S, Bieker S, Zentgraf U (2014). Senescence networking: WRKY18 is an upstream regulator, a downstream target gene, and a protein interaction partner of WRKY53. Journal of Plant Growth Regulation 33(1):106-118.

Ramamoorthy R, Jiang SY, Kumar N, Venkatesh PN, Ramachandran S (2008). A comprehensive transcriptional profiling of the WRKY gene family in rice under various abiotic and phytohormone treatments. Plant and Cell Physiology 49(6):865-879.

Rinerson CI, Rabara RC, Tripathi P, Shen QJ, Rushton PJ (2015). The evolution of WRKY transcription factors. BMC Plant Biology 15(1):118.

Rushton PJ, Somssich IE, Ringler P, Shen QJ (2010). WRKY transcription factors. Trends in Plant Science 15(5):247-258.

Rushton PJ, Torres JT, Parniske M, Wernert P, Hahlbrock K, Somssich IE (1996). Interaction of elicitor-induced DNA-binding proteins with elicitor response elements in the promoters of parsley $P R I$ genes. EMBO Journal 15(20):5690-5700.

Sakamoto H, Maruyama K, Sakuma Y, Meshi T, Iwabuchi M, Shinozaki K (2004). Arabidopsis Cys2/His2-type zinc-finger proteins function as transcription repressors under drought, cold, and high-salinity stress conditions. Plant Physiology 136(1):27342746.

Schepmann HG, PangJ, Matsuda SP (2001). Cloning and characterization of Ginkgo biloba levopimaradiene synthase, which catalyzes the first committed step in ginkgolide biosynthesis. Archives of Biochemistry and Biophysics 392(2):263-269.

Schmittgen TD, Livak KJ (2008). Analyzing real-time PCR data by the comparative CT method. Nature Protocols3(6):1101-1108.

Shen G, Pang Y, Wu W, Liao Z, Zhao L, Sun X, Tang K (2016). Cloning and characterization of a root-specific expressing gene encoding 3hydroxy-3-methylglutaryl coenzyme A reductase from Ginkgo biloba. Molecular Biology Reports 33(2):117-127.

Spyropoulou EA, Haring MA, Schuurink RC (2014). RNA sequencing on Solanum lycopersicum trichomes identifies transcription factors that activate terpene synthase promoters. BMC Genomics 15(1):402.

Stetter MG, Benz M, Ludewig U (2017). Increased root hair density by loss of WRKY6 in Arabidopsisthaliana. Peerj 5:e2891.

Sun LJ, Huang L, Li DY, Zhang HJ, Song FM (2014). Comprehensive expression analysis suggests overlapping of rice $O s W R K Y$ transcription factor genes during abiotic stress responses. Plant Physiology Journal 50(11):1651-1658.

Wang J, Tao F, An F, Zou Y, Tian W, Chen X, ... Hu X (2017). Wheat transcription factor TaWRKY70 is positively involved in hightemperature seedling-plant resistance to Puccinia striiformis f. sp. tritici. Molecular Plant Pathology 18(5):649-661.

Wang P, Liao Z, Guo L, Li W, Chen M, Pi Y, ... Tang K (2004). Cloning and functional analysis of a cdna encoding Ginkgo biloba farnesyl diphosphate synthase. Molecules and Cells 18(2):150-156.

Wang YQ, Shen JK, Berglund T, Ohlsson AB, Tang XF, Zhou ZK, ... Chen JN (2010). Analysis of expressed sequence tags from Ginkgo, mature foliage in China. Tree Genetics and Genomes 6(3):357-365.

Wei S (2010). Methyl jasmonic acid induced expression pattern of terpenoid indole alkaloid pathway genes in Catharanthus roseus seedlings. Plant Growth Regulation 61(3):243-251. 
Wei W, Zhang Y, Han L, Guan Z, Chai T (2008). A novel WRKY transcriptional factor from Thlaspi caerulescens negatively regulates the osmotic stress tolerance of transgenic tobacco. Plant Cell Reports 27(4):795-803.

Wu X, Shiroto Y, Kishitani S, Ito Y, Toriyama K (2009). Enhanced heat and drought tolerance in transgenic rice seedlings overexpressing OsWRKY11 under the control of hsp101 promoter. Plant Cell Reports 28(1):21-30.

Xie Z, Zhang ZL, Zou X, HuangJ, Ruas P, Thompson D, Shen QJ (2005). Annotations and functional analyses of the rice WRKY gene superfamily reveal positive and negative regulators of abscisic acid signalingin aleurone cells. Plant Physiology 137(1):176-189.

Xu F, Huang XH, Li LL, Deng G, Cheng H, Rong XF, ... Cheng SY (2013). Molecular cloning and characterization of GbDXS and GbGGPPS gene promoters, from Ginkgo biloba. Genetics and Molecular Research 12:293-301.

Xu F, Ning YJ, Zhang WW, Liao YL, Li LL, Cheng H, Cheng SY (2014). An $R 2 R 3-M Y B$ transcription factor as a negative regulator of the flavonoid biosynthesis pathway in Ginkgo biloba. Functional and Integrative Genomics 14(1):177-189.
Yang R, Fan X, Cai X, Hu F (2015). The inhibitory mechanisms by mixtures of two endophytic bacterial strains isolated from Ginkgo biloba against pepper phytophthora blight. Biological Control 85:59-67.

Yin G, Xu H, Xiao S, Qin Y, Li Y, Yan Y, Hu Yk (2013). The large soybean (Glycine max) WRKY TF family expanded by segmental duplication events and subsequent divergent selection among subgroups. BMC Plant Biology 13(1):148.

Zhang T, Tan D, Zhang L, Zhang X, Han Z (2017). Phylogenetic analysis and drought-responsive expression profiles of the WRKY transcription factor family in maize. Agri Gene 3:99-108.

Zhang Y, WangL (2005). The WRKY transcription factor superfamily: its origin in eukaryotes and expansion in plants. BMC Evolutionary Biology 5(1):1.

Zhou QY, Tian AG,ZouHF, XieZM,LeiG,HuangJ,... ChenSY(2008). Soybean WRKY-type transcription factor genes, GmWRKY13, GmWRKY21, and GmWRKY54, confer differential tolerance to abiotic stresses in transgenic Arabidopsis plants. Plant Biotechnology Journal 6(5):486-503. 